\title{
Relative importance of cigarette smoking in occupational lung disease*
}

\author{
P C ELMES
}

From the MRC Pneumoconiosis Unit, Llandough Hospital, Penarth, S Glamorgan CF6 $1 X W, U K$

ABSTRACT Since 1900 respiratory disease has remained a constant serious cause of chronic ill health and premature death in Britain. The falling importance of tuberculosis and pneumonia has been off-set by the rise in lung cancer. Bronchitis morbidity and mortality have fallen only slightly since 1935. To produce any real improvement in the future existing information as to cause must be studied. The relative contribution of occupational exposure is compared with the importance of cigarette smoking. Relevant information is scanty and has been produced to emphasise the existence of occupational diseases rather than assess their importance to the community as a whole. In Britain the evidence is that within the coal mining and iron and steel industries conditions are now such that dust exposure contributes little to the morbidity or mortality compared with the workers' smoking habits. Similar results have been shown by a cross-sectional survey of many dusty occupations in Western Germany. Only in the disappearing Welsh slate industry has dust disease been at least as important as smoking. Until the current regulations were introduced conditions existed among asbestos workers such that the combined effect of cigarette smoking and dust exposure led to a loss of life expectation of over 10 years in moderate smokers. Since the new regulations were introduced the risk for asbestos workers should approximate to that for other industrial workers. While control of occupational exposure to respiratory hazards remains important, a far greater improvement to respiratory health would be produced by controlling tobacco smoking.

Respiratory disease places a heavy burden on our society. In 1977 it caused 59m days' sickness absence and 118000 deaths in England and Wales. It was the most important cause of sickness absence and came second only to circulatory disease as a cause of death in that year (tables 1 and 2). During the past century the pattern of serious disease has changed, but its importance has not diminished. The reduction in disease due to infection has been offset by the increase in lung cancer. For those concerned with occupational diseases, respiratory disease is clearly important because of sickness absence. But it is also important as a cause of death before retiral age. Figure 1 shows the pattern of mortality in the 50-59 age group since 1911. There has been a 20 -fold reduction in deaths from tuberculosis and a 10-fold

*The Ernestine Henry Lecture delivered at the Royal College of Physicians London on 6 November 1979.

Received 26 March 1980

Accepted 1 May 1980
Table 1 Principal causes of deaths in England and Wales 1977-all ages: number of deaths. (Percentages in parentheses)

\begin{tabular}{lrrr}
\hline Cause & Men & Women & Total \\
\hline Circulatory disease & $143201(49)$ & $149395(52)$ & $292596(51)$ \\
$\begin{array}{l}\text { Respiratory diseases } \\
\text { (including cancer) }\end{array}$ & $70960(24)$ & $47260(17)$ & $118220(21)$ \\
Non-respiratory cancer & $40112(14)$ & $51098(18)$ & $91210(16)$ \\
All causes & 289773 & 286155 & 575928 \\
\hline
\end{tabular}

Mortality Statistics 1977. OPCS DH2 No 4.

Table 2 Principal causes of sickness absence in Britain 1977 (millions of days). (Percentages in parentheses)

\begin{tabular}{lccr}
\hline Cause & Men & Women & \multicolumn{1}{l}{ Total } \\
\hline Respiratory diseases & $48 \cdot 4(19)$ & $10 \cdot 8(17)$ & $59 \cdot 2(18)$ \\
Circulatory diseases & $44 \cdot 3(17)$ & $4 \cdot 6(7)$ & $48 \cdot 9(15)$ \\
Musculoskeletal disorders & $32 \cdot 2(13)$ & $6 \cdot 8(10)$ & $39 \cdot 0(12)$ \\
Mental disorders & $22 \cdot 2(9)$ & $9 \cdot 5(15)$ & $31 \cdot 7(10)$ \\
All causes & $256 \cdot 2$ & $65 \cdot 3$ & $321 \cdot 5$ \\
\hline
\end{tabular}

Social Security Statistics 1977, DHSS. 


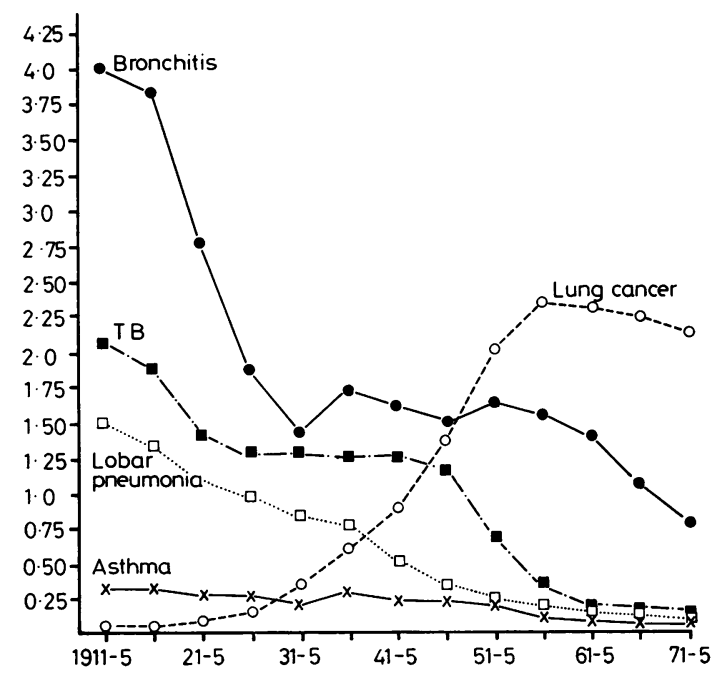

Fig 1 Pattern of deaths from respiratory disease since 1911 for men aged 55-59. For clarity line for bronchopneumonia has been omitted as it remained constant at about 0·3/1000 living a year throughout period. (From statistical reviews issued by RegistrarGeneral's Office and OPCS, HMSO.)

reduction for lobar pneumonia. Deaths from bronchitis fell dramatically between 1911 and 1935 but since then have fallen more gradually. Deaths from asthma seem to have fallen slightly (owing to a change in classification recently these figures for asthma are unreliable), while deaths from bronchopneumonia (not shown on the graph) have remained unchanged throughout the period at about 0.3 deaths per thousand living a year. The only respiratory disease to show an increase is cancer of the lung. The increase is not too dramatic in this age group but nevertheless lung cancer is now the most important cause of death, more than twice as important as bronchitis. Although the other respiratory diseases are unimportant causes of death in this age group, they are important causes of sickness absence from work. Lung cancer runs a comparatively short and fatal course so that it is underrepresented on sickness absence certificates and does not appear in fig 2. Since 1953 the main causes of sickness absence (other than influenza) have been bronchitis and tuberculosis. (Again because of changes in classification consistent figures for asthma are not available.)

To reduce the burden of respiratory disease we must consider the factors that may have influenced the disease in recent years. The causes may be listed as follows: (1) exposure to infective agents; (2) social factors, such as population density and

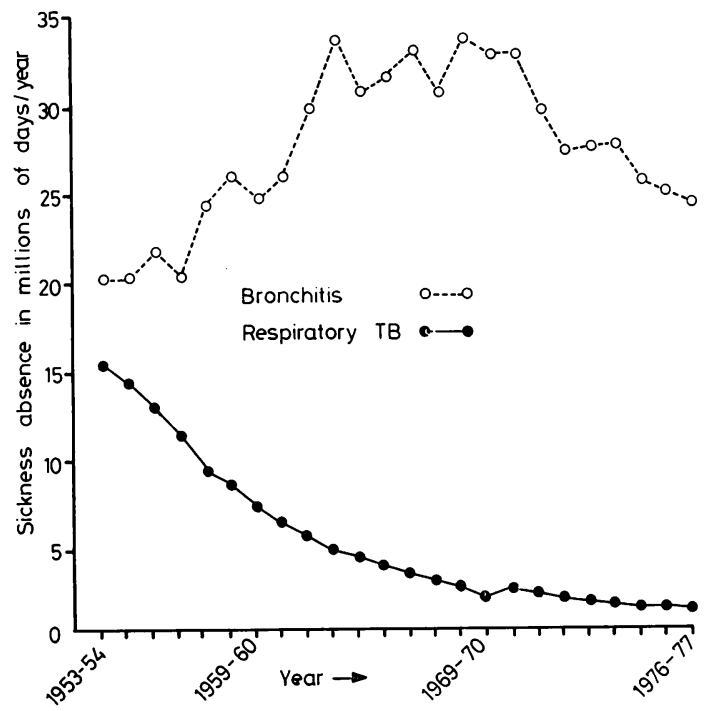

Fig 2 Pattern of sickness absence due to respiratory disease since 1953 for all ages. Figure for "all neoplasms" is well below Im days each year. Statistics for asthma alone are incomplete but appear to start at about $3 \mathrm{~m}$ days in 1953-4 and fall to about $2 \mathrm{~m}$ in 1969-70. (From annual reports of MOH DHSS, and Social Security Statistics, HMSO.)

nutrition; (3) exposure to non-infective toxic agents in the air; and (4) inherited susceptibility.

Apart from genetic counselling little can be done about inherited susceptibility, and indeed apart from rare conditions such as $\alpha$-antitrypsin deficiency there is little clear-cut evidence that inheritance is of great importance except in asthma. Infections may now be treated effectively with antibiotics, which may have contributed to the fall in mortality and sickness absence due to tuberculosis in the very recent past. But it is noticeable, both for lobar pneumonia and tuberculosis, that the initial introduction of effective treatment did not influence mortality immediately. For both these diseases social factors and possibly the isolation of infective cases were the main factors leading to the change observed, which should continue. Asthma is not due to infection, and bronchopneumonia is usually the terminal event in many illnesses not primarily due to infection. Social changes do not appear to have affected either asthma or bronchopneumonia.

Bronchitis presents a more complex picture. The major improvement occurred during a period when no specific treatment was available. Since 1935 another factor or factors has interfered with the improvement, and sickness absence rose between 
1955 and 1968. Both criteria show a slight improvement since then. These changes have occurred despite an increasingly wide range of antibacterial agents being available since the late 1930s. Indeed, the failure of the improvement in bronchitis statistics to be sustained could be interpreted as coinciding with the availability of these agents. Chronic bronchitis is more frequent in cigarette smokers and in dwellers in large conurbations suggesting that cigarette smoke and environmental atmospheric pollution are important. The recent improvement could be due to the effects of the clean air legislation or to a fall in smoking by older men or to both combined.

It is the view of many, expressed in the reports from the Royal College of Physicians ${ }^{1-3}$ that cigarette smoking is the main cause of the very serious increase in deaths from lung cancer that has occurred since 1920 . They would attribute the recent improvement to a tendency in older men to stop smoking, although it is also possible that cleaning of urban air has helped.

The two diseases of the chest that create the heaviest burden on our society are bronchitis and lung cancer. Asthma and related diseases are less important. Unless some new initiative is taken current evidence does not suggest that the situation in relation to these three diseases will improve. For both bronchitis and lung cancer cigarette smoking is a contributory cause, and atmospheric pollution by the products of fossil fuel combustion may also be a factor. Atmospheric pollution by organic materials in industry, agriculture, hobbies, and in the home is a factor in asthma and related diseases.

Sufficient evidence is available to recommend measures leading to a drastic reduction in cigarette smoking to relieve society of part of the burden of bronchitis and lung cancer. Complex arguments, however, have been brought forward that have blocked effective action so we must consider the importance of other factors to see whether other measures can be recommended that might be as effective as a reduction in cigarette smoking. As befits an Ernestine Henry lecture, "diseases due to occupation" will be considered to determine whether they contribute significantly to the burden of respiratory disease. A comparison will be made of the relative importance of toxic agents inhaled at work with the importance of inhaled cigarette smoke.

\section{Detection of occupational factors}

The industrial revolution created occupational diseases such as potter's asthma and miner's pneumoconiosis. It also created the social conditions that encouraged tuberculosis and atmospheric pollution which caused bronchitis. These two diseases have provided the main burden of lung disease, and their prevalence has obscured the contribution of occupational lung disease to the total burden. The Clean Air Acts and the present level of success in controlling tuberculosis have made it easier to recognise and measure the occupational contribution. An increasing flow of research has been published analysing the effects of various occupations on health. The research has been aimed at identifying occupational hazards. It has been assumed that these hazards should be removed regardless of the relative importance of the diseases they caused or the effects on the industry. Populations have been studied in relation to a particular hazard and compared either with the general population, with similar populations in other occupations, or with sub-populations within the same work force whose exposure is different. In all good studies allowance is made for age, sex, and smoking habits. In practice this can prevent a true comparison of the relative importance of the occupational hazard with that produced by tobacco smoke on the one hand or general levels of atmospheric pollution on the other. These research methods are forced on us because the lungs deteriorate with age.

"Aging" is a combined result of infective illnesses and time-weighted exposure to other non-occupational environmental factors as well as the aging process itself. As most of these factors affect the population as a whole the identification of an occupational factor is easiest to achieve by standardising for all the other factors in combination rather than by considering each separately.

Studies of occupational disease are seldom complete but are carried out in stages. It is usual to start by examining men currently at work for evidence of a particular disease whose existence has been suggested by case reports. This stage is the "crosssectional survey" and once identified the population may be followed up to determine the progress of existing cases of disease and to measure the attack rate of new cases. At this stage it becomes a "cohort" study, whose value may be increased by identifying the working population at some time in the past and combining a retrospective with a prospective procedure. The incidence and severity of the disease may be identified on medical grounds by questionnaires, examinations, and tests during life. Alternatively, it may be done by sickness-absence certification or studying the reasons for premature retiral. Finally, the population may be followed until death and the effect measured in terms of lost life expectation or an unexpected distribution of causes of death.

Evidence about occupational respiratory disease 


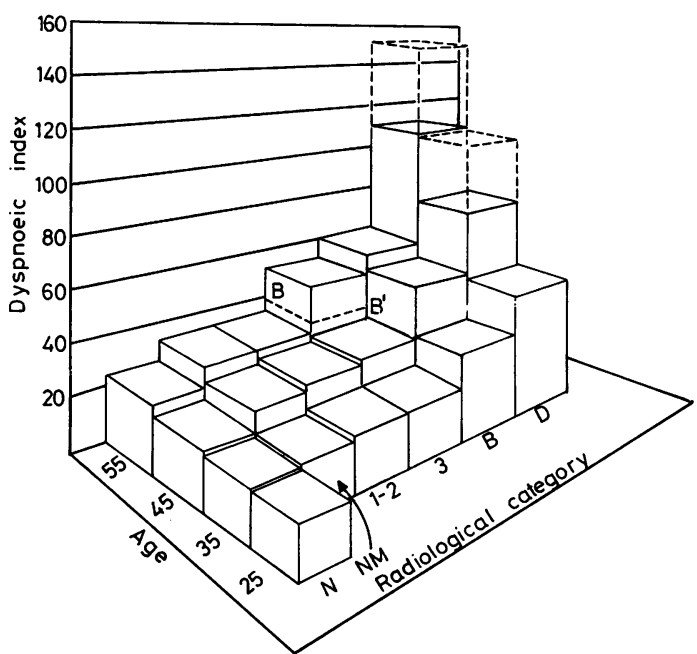

Fig 3 Relation between age, dust exposure (as measured by $x$-ray category), and lung function in coal miners in Britain 1955. Dyspnoeic index =

$$
\frac{\text { standardised ventilation } \times 100}{\text { maximum voluntary ventilation }}
$$

and was used as a measure of breathlessness or disability. It is seen to increase slightly with age in non-miners $(N)$ and in miners with none or simple pneumoconiosis (NM to category 3). These categories are all slightly more breathless than non-miners in all age groups. A serious increase in breathlessness occurs in all age groups with complicated disease (categories $B$ and $C$ ). Gilson and Hugh-Jones ${ }^{4}$ give reasons for disregarding part of column above dotted line joining $B$ to $B^{\prime}$.

has been accumulated over many centuries. But, apart from descriptive studies establishing the existence of these diseases, little quantitative work has been done until recently. The most extensively studied group is coal miners.

\section{Coal workers}

A series of cross-sectional studies carried out in Britain before and after the 1939-45 war showed that coal workers' pneumoconiosis was dustdose related. Unexpectedly, the frequency and severity of simple pneumoconiosis was closely related to the cumulative dose of total respirable dust rather than to the dose of crystalline silica that occurs in varying proportions in the dust. The second unexpected finding was that while the $x$-ray shadows of dust disease remained discrete (simple) there was little disability, but as soon as the shadows coalesced (became "complicated") disability and pronounced disturbance of lung function occurred (fig 3). Complicated disease, called progressive massive fibrosis, did not usually appear until a certain profusion of discrete shadows was present. Up to that stage the disease did not progress without further dust exposure, but once the massive shadows appeared, they and the deterioration in lung function progressed after the men had left the pit. At that time, in the 1950s, the analysis did not show any relation between cumulative dust exposure or $x$-ray changes and the symptoms and physiological changes of bronchitis. ${ }^{4}$ The effect of cigarette smoking was not considered. These findings led to the present system of health supervision in the mines by which men are advised to stop doing dusty jobs when the radiographic changes reach category 2 . At this stage they are entitled to compensation in the absence of detectable disability and are extremely unlikely to progress to disabling disease if they stop dusty work. In another cross-sectional study based on the year 1962, Liddell ${ }^{5}$ showed that miners took more time off in more spells due to sickness even than men in other arduous occupations. The time off increased with age and was associated with various diagnoses but mainly respiratory illness and injuries. One could conclude that the high sickness absence was not due to dust because the worst affected groups underground were not those with the highest exposure. This finding showed a major source of error in crosssectional surveys due to selection within the population. The earlier surveys had already shown that young men at the coal face had better respiratory function than average for men of that age because fitness is a prerequisite for this arduous work, which is also the most dusty. As time goes by some face workers become less fit (more often ill) and move away from dusty arduous work taking their high morbidity with them. This source of error may be avoided by carefully planned longitudinal studies using cumulative dust exposure rather than current exposure category as an index of exposure.

A thorough cross-sectional study of symptoms and respiratory function in miners has been carried out in Germany as part of an industry-wide study on the causes of bronchitis. ${ }^{6}$ In this study exposure to dust and other respiratory "noxae" was measured and used to classify workers into grades. Respiratory symptoms were recorded using a Medical Research Council-type questionnaire and careful measurements of respiratory function carried out aimed at detecting both airways disease and damage to the alveoli (emphysema). Chest radiographs were taken to detect pneumoconiosis as well as unrelated lung diseases. They were not used as a method of measuring dust exposure or its effects. The findings are reported with a standard format for the workers in all the industries. Examples of the figures and tables are given in fig 4 and table 3. Seventeen hundred 


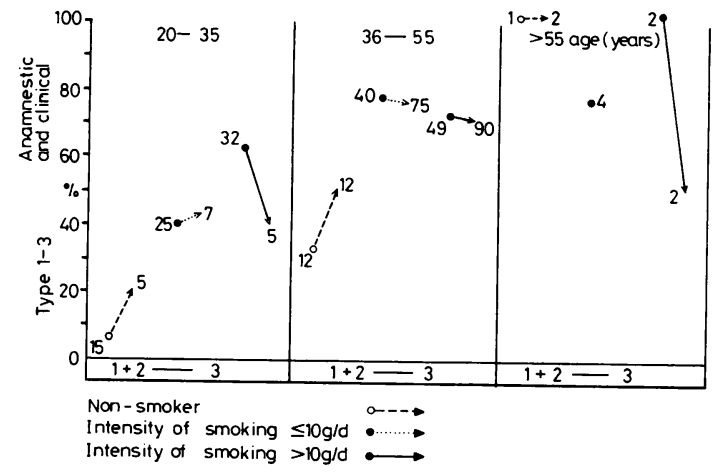

Fig 4 Coal mine, active staff. Example of data presentation in German cross-sectional study of coal miners. In left-hand section prevalence of bronchitic symptoms in age group 20-35 is shown separately from non-smokers, those smoking up to $10 \mathrm{~g}$ of tobacco a day, and those smoking over $10 \mathrm{~g} /$ day. Dot at beginning of each line represents prevalence of symptoms for men with a low level of dust exposure (categories 1 and 2). Arrow at end of line represents prevalance in heavily exposed group (category 3). Numbers by dots and arrows indicate number of workers in each category. Similar information is displayed for 36-55 age group in central section. Information for over-55 age group (right hand section) is incomplete because numbers of workers in sub-categories were inadequate. Figure shows that symptoms of bronchitis in coal miners are more frequent in men with high dust exposure who smoke heavily. Frequency increases with age but the separate effect of smoking and dust exposure ceases to be obvious.

Table 3 Unweighted mean excess prevalence of bronchial reaction in relation to smoking, age, and dust ${ }^{6}$

\begin{tabular}{|c|c|c|c|c|}
\hline \multirow[t]{2}{*}{ Decision function } & \multirow[t]{2}{*}{ Dust } & \multicolumn{2}{|l|}{ Smoking } & \multirow[t]{2}{*}{ Age } \\
\hline & & $\begin{array}{l}1-10 \mathrm{~g} \\
\text { tobacco/day }\end{array}$ & $\begin{array}{l}>10 \mathrm{~g} \\
\text { tobacco/day }\end{array}$ & \\
\hline $\begin{array}{l}\text { Anamnestic and clinical } \\
\text { (ABR) } \\
\text { Function analysis }\end{array}$ & $4 \cdot 7$ & $34 \cdot 3$ & $37 \cdot 7$ & $24 \cdot 7$ \\
\hline $\begin{array}{l}\text { indicators (Fov) } \\
\text { Combination (Kov) }\end{array}$ & $\begin{array}{l}4 \cdot 3 \\
5 \cdot 3\end{array}$ & $<\frac{1}{12 \cdot 7}$ & $<1$ & $\begin{array}{c}9 \cdot 3 \\
25\end{array}$ \\
\hline Emphysema (FLU) & $10 \cdot 3$ & $3 \cdot 3$ & $<1$ & 2 \\
\hline
\end{tabular}

miners were selected at random from the general population of coal miners in a large number of pits, also nearly 400 pensioners and 820 men with varying degrees of "silicosis" (pneumoconiosis).

Smoking and age were the most important causes of the symptoms of bronchitis, although dust often contributed to a minor but statistically significant degree. In pensioners and in men still working after the age of 55 the incidence of symptoms was frequent, but it was difficult to separate the influence of dust and smoking from that of age, partly because there

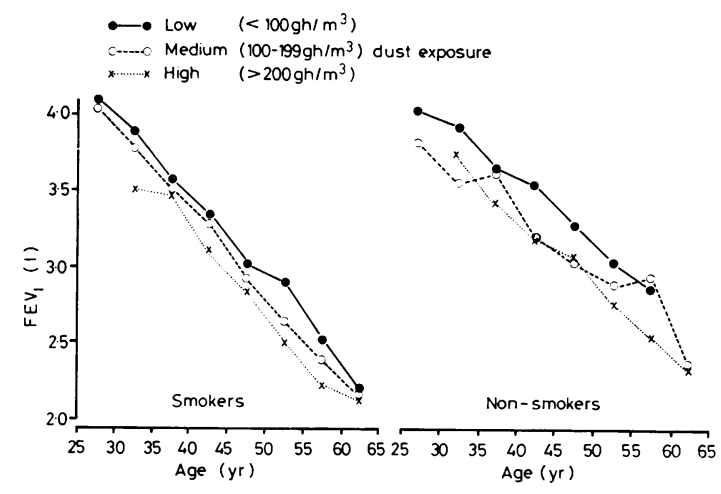

Fig 5 Falling fast expiratory volume $\left(F E V_{1}\right)$ with age in British miners related to cumulative dust exposure and cigarette smoking. Those with high dust exposure have lower initial $F E V_{1}$ but rate of decline is same as for those with low dust exposure. Smokers show a more rapid rate of decline than non-smokers. ${ }^{7}$

were so few non-smokers. There was little evidence that smoking or dust led to airways obstruction up to the age of 55. Only in men with severe pneumoconiosis was there an obvious increase in airways obstruction not attributable to age or smoking habits. The authors showed that coal mining produced a higher incidence of bronchitis than the other industries and postulate that this is due to the high dust levels in all mining jobs, which obscures the effect of dust in the "within industry" comparisons.

In the 1950 s a longitudinal study in 20 pits scattered over British coalfields was set up by the National Coal Board and is now yielding information that cannot be gained from cross-sectional studies. It has confirmed the close relation between cumulative respirable dust exposure and the presence and profusion of the shadows of simple pneumoconiosis. Rogan et $a l^{7}$ showed that there was a progressive decline in ventilatory capacity with age that was greater in smokers than non-smokers (fig 5). Although in each age group the men in the dustiest jobs had a slightly lower $F E V_{1}$ than men in less dusty jobs, their rate of decline was the same. The age-related regression coefficients were the same for each dust group, which suggests that the differences were due to some change in the airways related to current dust exposure, which did not get worse with age. The group studied, however, was a survivor population from which men developing progressive massive fibrosis were also excluded. This study also showed a slight fall in FEV with increasing profusion of small opacities, but it was not possible to separate this from the dustrelated effect already discussed, which occurred equally in men with and without $x$-ray changes. This is presumably the dust effect detected in the 
German study where, being non-progressive, it was not obvious in the older men.

The effect of cigarette smoking on British coal miners has been studied in more detail by Jacobsen ${ }^{8}$ using the National Coal Board data. The earlier study $^{7}$ had shown that the FEV declined more rapidly in smokers than non-smokers irrespective of dust exposure (fig 5). In the more detailed study no relation was found between smoking and the size or profusion of simple pneumoconiosis shadows. Smoking appeared to be the main, if not the only, factor causing respiratory symptoms and disability in miners without massive fibrosis.

The ultimate test of occupational disease lies in mortality studies. Permanent damage to the lungs causes a reduction in life expectation and an increase in the proportion of respiratory compared with nonrespiratory causes of death. Liddell ${ }^{9}$ studied deaths recorded by the Registrar-General occurring in coal miners aged under 65 . The standardised mortality rate for miners was below that of the general population, lowest in the dustiest jobs, and approximating to the rest of the population in surface workers. Deaths from coal worker's pneumoconiosis occurred more often in surface than in coal-face workers, who had exceptionally low rates for pneumonia, bronchitis, and lung cancer. These anomalous findings were due to the "fit-worker" effect and difficult to interpret because no attempt was made to trace workers who had left the industry more than ten years previously or to extend the study past the retiring age.

Cochrane's exemplary study ${ }^{10}$ of the Rhondda and Leigh populations, however, included both those who had left the mine early and those who had

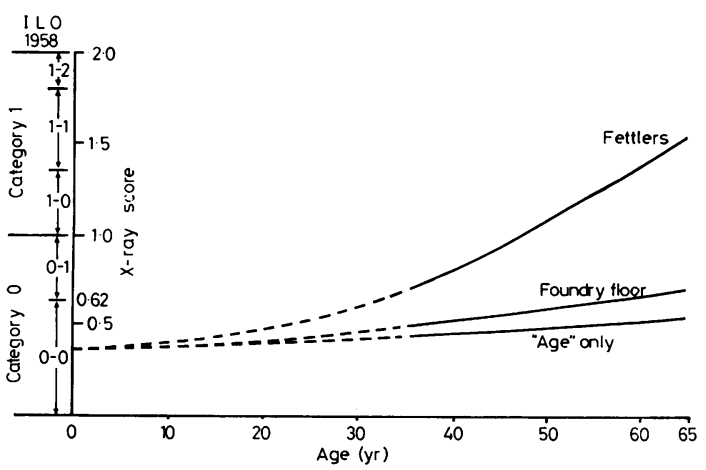

Fig 6 Estimated profusion of simple pneumoconiosis in foundry workers related to age. Each curve predicts average reading on ILO scale for men who started work at 15. After 40 years' work foundry workers would average a score of $0 / 1$ whereas fettlers average $1 / 1$ on ILO scale. ${ }^{12}$ retired at the normal age. The Rhondda miners had a raised standardised mortality ratio of between 115 and 120 except those who had moderately advanced or advanced massive fibrosis at the beginning of the study. The men with massive fibrosis had a ratio of 195. The ratios for bronchitic deaths were high (circa 200) and for lung cancer low (circa 70). In the Leigh population the mortality for miners without massive fibrosis was the same as that for nonminers. The lack of correlation between the level of dust damage detected by radiographs and the deaths from respiratory disease in all miners without severe massive fibrosis in both these populations suggests that factors other than dust are dominant. Unfortunately Cochrane did not include the effects of smoking in these studies.

Rook et al ${ }^{11}$ suggest that smoking is the determining factor for lung cancer in Lancashire coal miners. In analysis of necropsy findings they found carcinoma of the lung in $11.4 \%$, not significantly different from other male workers in the area. Thirteen per cent of miners without pneumoconiosis died of lung cancer whereas only $8.4 \%$ of those with progressive massive fibrosis died of cancer, although in this series they lived to an average of 72 years, about a year longer than those with simple pneumoconiosis.

\section{Iron and steel workers}

Iron and steel foundries used to be dirty, dangerous places. The Registrar-General's tables for $1951^{12}$ indicated an excess mortality from non-malignant (SMR 210) and malignant (SMR 150) respiratory disease. A cross-sectional survey was carried out on a 1:40 sample of foundries in Britain in 1964-5.13

There was a simple pneumoconiosis that was exposure related (fig 6). There was more $x$-ray change in fettlers than in foundry floor workers, and it was enhanced by smoking in the latter. None developed progressive massive fibrosis. Symptoms of bronchitis increased with age and exposure (fig 7). The effect of smoking 25 or more cigarettes a day in non-foundry workers seemed to equal the effect of foundry dust in non-smokers and the combined effects seem additive. Surprisingly, although 2000 workers were studied the contribution of dust to the incidence of bronchitic symptoms was not found to be statistically significant, and there was no evidence that dust contributed to the fall in lung function usually associated with bronchitis.

Lowe et al $^{14}$ studied the population of two large steel works in South Wales in the 1960s and were unable to detect any factors other than cigarette smoking as causing respiratory disease or loss of ventilatory capacity. They also found that the levels of dust and especially sulphur dioxide in these plants 


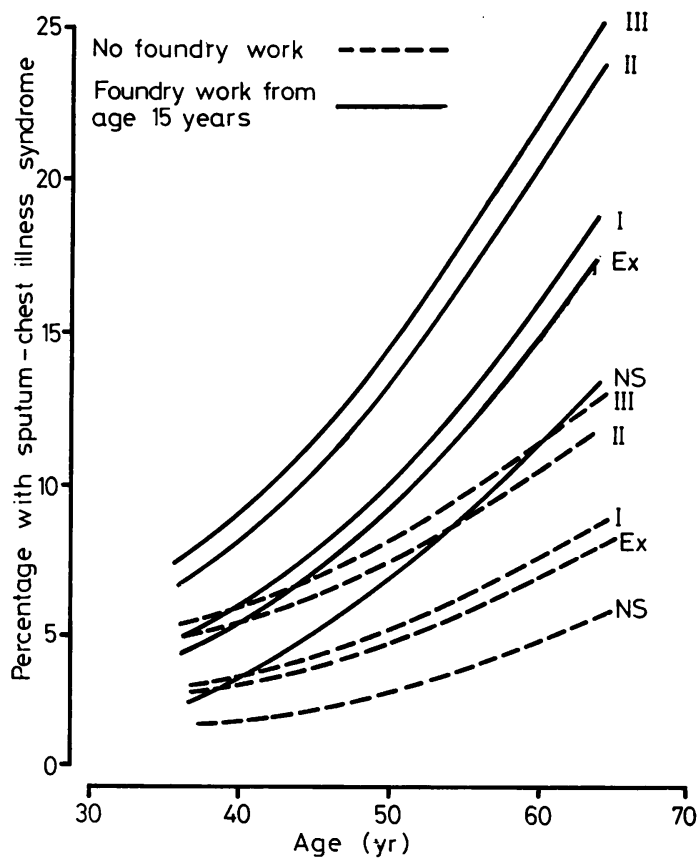

Fig 7 Estimated prevalence of bronchitic symptoms in foundrymen related to age and cigarette smoking. There were five categories of smoker (NS = non-smoker, $E x=$ ex-smoker, $I=1-14$ cigs a day, $I I=15-24$, and $I I I=25$ or over.) By retiral age smoking produces more than a two-fold increase in bronchitic symptoms in both foundry men and non-foundry men. Foundry work has same effect on non-smokers as category 3 cigarette smoking has on non-foundry workers. Combined effect is about a five-fold increase. ${ }^{12}$

were lower than those prevailing in the streets of central London at the time.

The German cross-sectional study 6 of about 6500 workers in steel works and foundries included some heavy engineering workers. Both smoking and age were considerably more important than dust in causing bronchitic symptoms in all the groups. Smoking was more important than age in some works and less important in others. Smoking and age contributed to the level of airways obstruction and emphysema in some of the older men, dust did not.

It is difficult to reconcile the results of these crosssectional studies with the mortality findings listed by the Registrar-General ${ }^{12}$ already quoted. It is true that the mortality relates to conditions that may have ceased to exist by the time the surveys were carried out. But the figures for 1971 quoted in the official report for 1970-2 lists an overall mortality ratio of 122 with 155 for lung cancer and 167 for nonmalignant respiratory disease. ${ }^{15}$ Grundy ${ }^{16}$ in a partial follow-up of the South Wales steel workers confirmed that the high death rate for lung cancer is still present and is not accounted for by smoking habits. More cohort studies are needed.

\section{Slate workers}

A study of slate workers in North Wales has finally shown that they develop dust-related disease.17 Previous studies had failed, perhaps because of the high incidence of pulmonary tuberculosis and because measurements of dust exposure and respiratory function were not carried out. Even for this recent study, accurate dust measurements were not available, and the workers had to be classified into job groups according to the relative level of past and present exposure. The level of simple pneumoconiosis was found to be related to the duration and severity of exposure.

Figure 8 shows the relation between $x$-ray change and breathlessness. The prevalence of breathlessness increases most rapidly in those with pronounced $x$-ray changes (final category 3 ). The difference between smokers and non-smokers is greatest where the dust has had least effect (final category 0 ). The importance of smoking decreases with increasing dust effect. Figure 9 shows the relation between $x$-ray

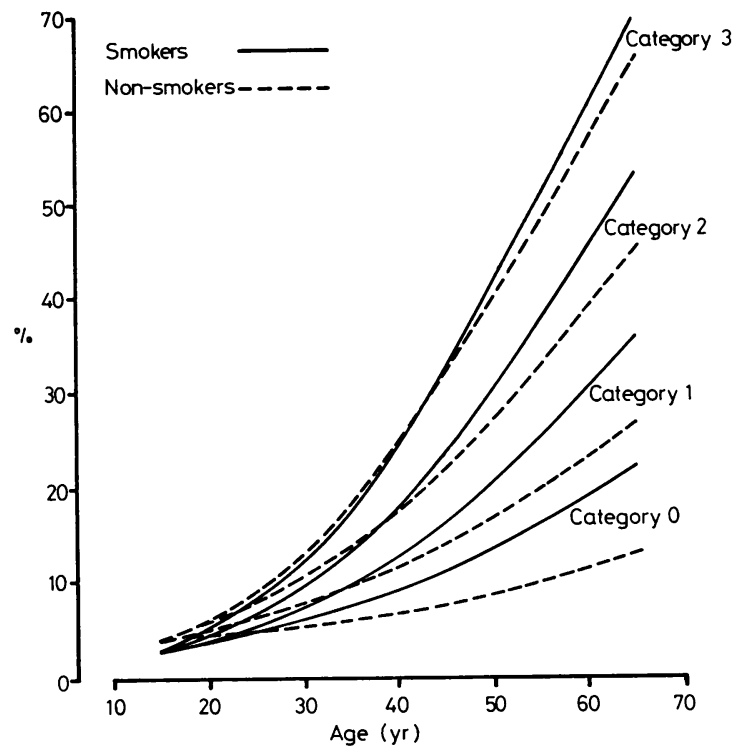

Fig 8 Prevalence of dyspnoea in slate workers.

Prevalence of MRC questionnaire breathlessness (grade 2) is plotted against age. Dust effect is shown as $x$-ray change on ILO classification finally achieved at age 65 . Increase is greatest in those who finally show most dust disease. Smoking increases prevalence of symptoms most in those with least severe $x$-ray changes. ${ }^{17}$ 


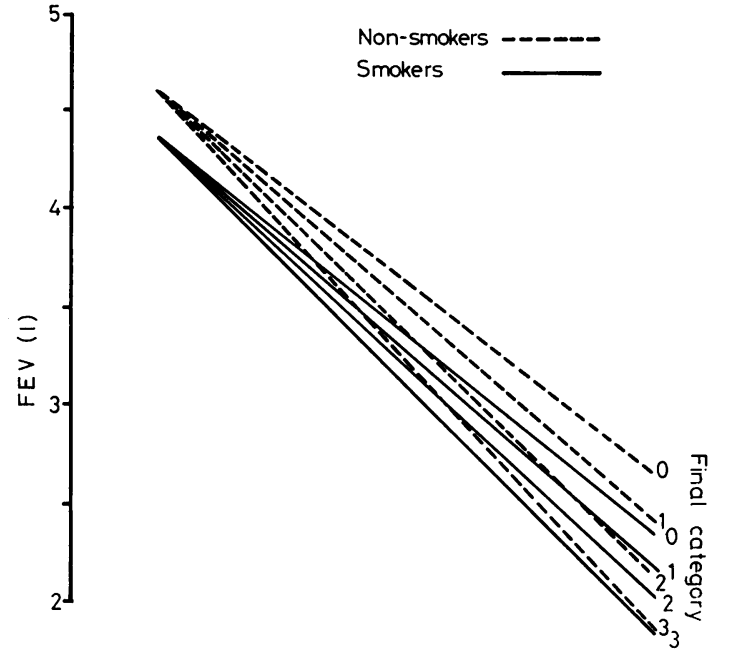

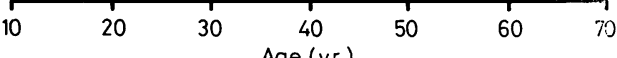

Fig 9 Decline in FEV in smoking and non-smoking slate workers. Rate of decline has been shown separately for smokers and non-smokers according to $x$-ray category reached at age 65.17

changes, age, and an objective measurement of respiratory disability. The fast expiratory volume declines more rapidly in those with the most $x$-ray change. The steepest decline is seen in non-smokers who developed category 3 disease. The decline in smokers of the same $x$-ray category was not as steep. This implies that the effect of dust is greater than the effect of smoking or that their combined effect is less than additive due to interference between the two factors. Without measurements of dust levels it is not possible to equate the airways effects of any level of dust exposure with any level of cigarette smoking.

The pattern of disease in slate workers differs from that in coal workers in two respects. Firstly, there is an obvious relation between dust exposure and measured disability before massive fibrosis occurs. Secondly, the simple pneumoconiosis progresses to massive fibrosis long after exposure ceases. The follow-up study of the effect of this dust on life expectation and the causes of death has not been carried out.

\section{Asbestos workers}

Asbestos releases a dust that consists of elongated particles (fibres) that are more readily retained in the lung than the dusts considered up to now. Dust levels that are not perceptible to the naked eye are associated with an increased risk of pulmonary disease. The danger of lung fibrosis was well documented by HM's Factory Inspectorate in 1930 when Merewether and Price ${ }^{18}$ showed that fatalities could occur within 15 years of first exposure. Regulations introduced in 1933 reduced this risk considerably, and premature deaths due to uncomplicated asbestosis are now rare. Asbestos dust is much more difficult to measure than dusts composed of isometric particles, and measurements by weight or number of fibres may be inappropriate without detailed size distribution measurements including both lengths and diameters. Because exposure measurements have been inadequate, cross-sectional and longitudinal studies of asbsetos workers have so far failed to produce reliable information on the cumulative dose needed to cause detectable, certifiable, or life-threatening asbestos-related disease. The shadows on radiographs are unlike those in other pneumoconioses in that they are linear and not rounded, affect the lower zones first, and are associated with shrinkage of the lung tissue. There may be both diffuse and discrete thickening of the pleura.

While the 1933 regulations reduced the incidence and severity of asbestosis in those sections of the industry to which they were applied, they also lead to the detection of the second and most important fatal asbestos-related disease-primary lung cancer. By 1960 over half of the men certified as having asbestosis by the pneumoconiosis panels were dying with lung cancer. ${ }^{19}$ Surveys of working populations had not detected this hazard because men seldom remain at work for long with detectable lung cancer. It was because the pneumoconiosis compensation scheme included necropsy examination before the payment of widows' benefit that this association was documented. The much rarer cancer, mesothelioma of the pleura or peritoneum, was first associated with asbestos exposure around the crocidolite mines of the North-western Cape Province of South Africa. ${ }^{20}$

McDonald $^{21}$ has summarised the epidemiological evidence concerning asbestos-induced mesothelioma. Of the three types of asbestos in commercial use, crocidolite is most likely to cause mesothelioma when mined or when being used in industry. But in the United States amosite may be as important, ${ }^{22}$ although it has caused few mesotheliomas where it is mined in South Africa. The incidence of mesothelioma in an industrial population has been shown to be dose related, ${ }^{23}$ but the long latent period and lack of dust measurements over the relevant period has made it impossible to put the relationship on a quantitative basis.

In comparing the asbestos hazards with other environmental factors, such as cigarette smoking, the lack of information on past exposure is only part of the difficulty. There seems to be an interaction be- 
Table 4 Men working in asbestos textile factory in England

\begin{tabular}{|c|c|c|c|c|c|}
\hline & \multirow{2}{*}{$\begin{array}{l}\text { No } \\
\text { of } \\
\text { men }\end{array}$} & \multicolumn{4}{|c|}{ Percentages with signs } \\
\hline & & $\begin{array}{r}\text { Crackles } P \\
a\end{array}$ & $\begin{array}{l}\text { Possible } \\
\text { asbestosis }\end{array}$ & $\begin{array}{l}\text { Certified } \\
\text { asbestosis }\end{array}$ & $\begin{array}{l}\text { Small } \\
\text { opacities }\end{array}$ \\
\hline $\begin{array}{l}\text { Non,'light smokers } \\
\text { Medium/heavy }\end{array}$ & 55 & 0 & 0 & 0 & 4 \\
\hline smokers & 116 & 19 & 9 & 7 & 19 \\
\hline Ex-smokers & 24 & 17 & 13 & 8 & 17 \\
\hline
\end{tabular}

tween smoking and dust in the cause of asbestosis and lung cancer but not mesothelioma. The evidence concerning this has built up gradually, starting with the cross-sectional surveys. These surveys have shown that increasing dust exposure is associated with $x$-ray changes and reduction in vital capacity, and $\mathrm{FEV}_{1}$, and basal rales. A reduction in gas transfer without evidence of airways obstruction is typical in workers with relatively advanced disease under the age of 50. But in older men the symptoms of bronchitis and evidence of airways obstruction are also present, and it is difficult to separate these effects from the effects of smoking. The German study ${ }^{6}$ included about 500 asbestos workers. Bronchitic symptoms were seen in smokers with high dust exposure but not in non-smokers. It is the only group of workers in this large study where no relation between smoking alone and bronchitic symptoms was shown. This study, like many others, also failed to show evidence of a risk of cancer.

The more detailed studies of two populations in Britain have been analysed to investigate the original suggestion made by Weiss ${ }^{24}$ that smoking increased lung fibrosis in asbestos workers. ${ }^{25}$ Both in an asbestos textile mill and in the dockyard workers in Plymouth the cross-sectional studies showed that the prevalence of early signs of asbestosis (crepitations and small opacities) was higher in smokers than nonsmokers allowing for age and exposure. Advanced (certifiable) asbestosis was also more common in smokers. Table 4 shows the analysis for the textile workers.

Longitudinal studies show that established asbestosis may progress, slowly, after exposure has ceased or under the reduced dust conditions laid down by present legislation. Analyses of this progression in relation to smoking have not been published, but the cohort studies do show a significant fall out of deaths from asbestosis, cancer, and mesothelioma. As the cohorts are followed the populations' age and the pattern of deaths change to include an increasing proportion of deaths unrelated to exposure. The fact that the premature, occupationally related deaths tend to be grouped into the first half of the total mortality of a cohort has led to an exaggeration of

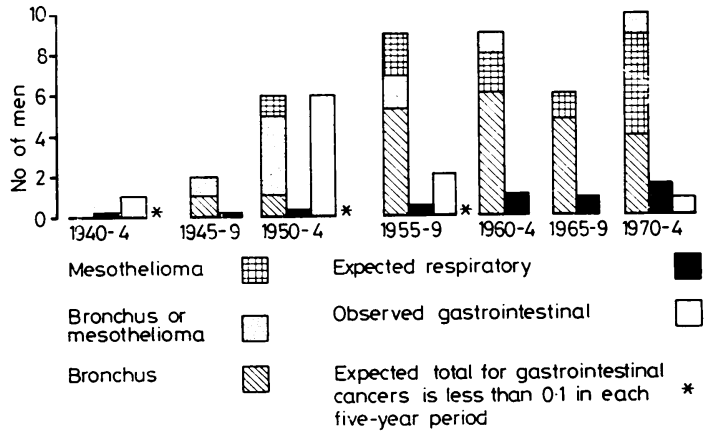

Fig 10 Cancer deaths in cohort of Belfast insulation workers. If half of "bronchus or mesothelioma" deaths are included ratio of observed to expected lung cancer deaths in 1955-9 is 20:1 and in 1970-4 less than 3:1.

the importance of hazards. The well-studied cohorts of asbestos workers have been analysed by the most sophisticated statistical techniques with standardising for age, sex, and social class, and the results are expressed first as standardised mortality rates and then as ratios comparing the exposed groups with the general population. By this sort of method insulation workers show a very high risk..$^{26} 27$

In the early years of follow-up the Belfast cohort had a 20 -fold increase in risk of lung cancer compared with the general population in Belfast (fig 10). As $10 \%$ of men in Belfast die eventually of lung cancer the 20-fold increase for working with asbestos cannot be maintained, and indeed the long-term follow-up confirms an apparent reduction in risk. In the larger American study of insulation workers there appeared to have been risk ratios as high as 87-fold (heavy smokers) or 36-fold (ex-smokers).

Saracci ${ }^{28}$ has pointed out that all the populations so far studied are lacking in two important respects: (1) the non-smokers exposed to asbestos are too small in number; and (2) there were no non-smoking non-exposed groups within the studies. Controls were usually derived from the general population statistics including smokers.

In most of the earlier reports no deaths from lung cancer in non-smokers were recorded, and this was interpreted as indicating that asbestos did not increase the risk of cancer in non-smokers. Lung cancers, however, have now been recorded in nonsmoking women who worked with asbestos in Britain. The figures available have been reanalysed ${ }^{25}$ (table 5) to determine the relation among smoking, asbestos, and lung cancer. There is an obvious excess of lung cancer in the smoking groups in the male insulation and factory workers and in the female factory workers. The number of cancers observed correlated closely to that calculated using 
Table 5 Distribution of lung cancers in asbestos workers by smoking habits

\begin{tabular}{|c|c|c|c|c|}
\hline & \multirow[t]{2}{*}{$\begin{array}{l}\text { Observed } \\
\text { deaths }\end{array}$} & \multirow{2}{*}{$\begin{array}{l}\text { Expected } \\
\text { non-occupational } \\
\text { deaths }\end{array}$} & \multicolumn{2}{|c|}{$\begin{array}{l}\text { Expected deaths } \\
\text { (including occupational) }\end{array}$} \\
\hline & & & $\begin{array}{l}\text { Additive } \\
\text { model }\end{array}$ & $\begin{array}{l}\text { Multiplicative } \\
\text { model }\end{array}$ \\
\hline $\begin{array}{l}\text { Cigarette } \\
\text { smokers }\end{array}$ & 24 & $3 \cdot 0$ & 18.9 & 22.6 \\
\hline $\begin{array}{l}\text { Others } \\
\text { Men }\end{array}$ & 0 & 0.2 & $5 \cdot 1$ & 1.4 \\
\hline Smokers & 32 & $12 \cdot 0$ & $31 \cdot 4$ & $33 \cdot 1$ \\
\hline $\begin{array}{l}\text { Non-smokers } \\
\text { Women }\end{array}$ & 0 & 0.0 & $1 \cdot 2$ & $0 \cdot 1$ \\
\hline Smokers & 18 & 1.9 & $14 \cdot 6$ & $17 \cdot 8$ \\
\hline Non-smokers & 2 & $0 \cdot 2$ & $5 \cdot 4$ & $2 \cdot 2$ \\
\hline
\end{tabular}

Table 6 Insulation workers lung cancer $^{29}$

\begin{tabular}{lllrrr}
\hline Group & $\begin{array}{l}\text { Exposure } \\
\text { to } \\
\text { asbestos? }\end{array}$ & $\begin{array}{l}\text { History } \\
\text { cigarette } \\
\text { smoking? }\end{array}$ & $\begin{array}{l}\text { Death } \\
\text { rate }\end{array}$ & & \\
& difference & $\begin{array}{l}\text { Matio } \\
\text { ratity }\end{array}$ \\
\hline Control & No & No & $11 \cdot 3$ & $0 \cdot 0$ & $1 \cdot 00$ \\
Asbestos workers & Yes & No & $58 \cdot 4$ & $+47 \cdot 1$ & $5 \cdot 17$ \\
Control & No & Yes & $122 \cdot 6+111 \cdot 3$ & $10 \cdot 85$ \\
Asbestos workers & Yes & Yes & $601 \cdot 6+590 \cdot 3$ & $53 \cdot 24$ \\
\hline
\end{tabular}

a multiplicative model. But the lack of adequate numbers in the non-smoking groups means that this conclusion can only be tentative.

As time passes and the cohorts grow older the situation becomes clearer. The latest analysis of the American insulation workers ${ }^{29}$ compares them with a carefully selected control group from the general population (table 6). The risk of cigarettes alone appears to be a 10-fold increase in lung cancer. For asbestos in non-smokers the risk is about five-fold, and the difference in risk between no asbestos exposure and asbestos exposure in smokers is also fivefold. The combined risk is almost exactly that predicted for arithmetic model (53-fold). This risk ratio cannot be used to predict the ultimate proportion of deaths from smoking or asbestos or both in this population, but it seems likely that smoking is twice as important as asbestos for lung cancer. Deaths from mesothelioma (not attributable to smoking) were estimated as being between a quarter and half of those from lung cancer and were about the same in number as those attributed to asbestosis (to which smoking does contribute). On the aggregate it appears that in this relatively heavily exposed group cigarette smoking is rather more important in causing deaths from respiratory disease than asbestos dust.

Other methods of comparing mortality experience may be applied to this type of cohort material. ${ }^{27}$ When analysed in the usual way an excess of observed over expected respiratory cancers was seen in each successive five-year period. The cohort con-

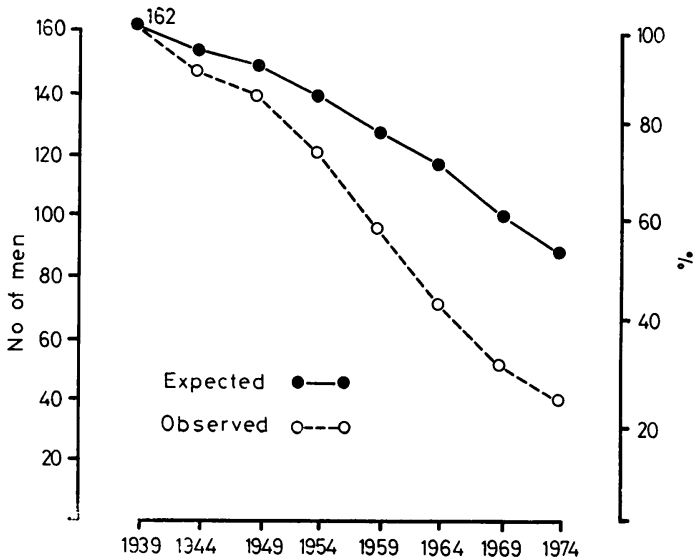

Fig 11 Survival of 162 Belfast insulation workers compared with men of same age and social class over same period in N Ireland. From 1949 to 1969 a significantly greater number died due to all causes than was expected in each five-year period.

tained men of all ages when it was first identified in 1940 , and the older men tended to die first. Nevertheless, the mean age of the cohort rose and the ratio of observed over-expected for primary lung cancer fell from 20:1 to less than 3:1 between 1950-4 and 1970-4. The mean age at death rose from 55 to 66 in the same period. If the experience is expressed as a survival curve (fig 11) the mortality for all causes may be compared with the rest of the population. Death rates are higher (the slope of the curve is steeper) than for the expected until the last five years when they run parallel. In this cohort it was not

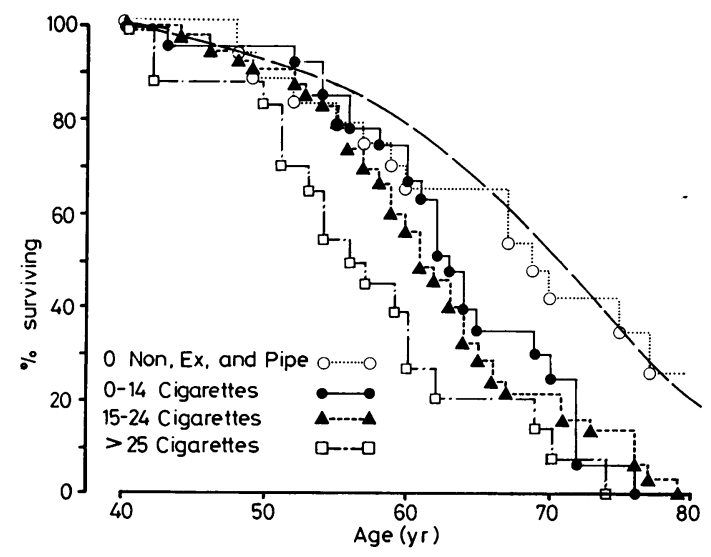

Fig 12 Survival of Belfast insulation workers divided into smoking categories compared with all $N$ Ireland men (smokers and non-smokers) of same age and social class. 
possible to show a relation to cumulative dust exposure because no measurements were made. Duration of exposure appeared to have no influence, in that the mortality was as high in the men with short exposure as it was in those with long. Therefore one can only compare the effect of different levels of smoking with a single level of asbestos exposure (fig 12).

Bearing in mind the small total numbers in this cohort and that smoking history was not available for all of them there is a remarkably clear separation of the risk by smoking habit. The $50 \%$ death point for the control population is 72 years and for all the insulators is 61 , indicating an average loss of life expectation of 11 years. For the heaviest smokers the $50 \%$ death point is 53 (loss of 19 years), the moderate smokers 61 (loss 11 years), light smokers 62 (loss of 10 years), and the non-, ex-, and pipe smokers 66. Taking the entire curve instead of the $50 \%$ death point the experience of the non-, ex-, and pipe smokers appears to approximate to the control population, indicating that asbestos by itself carries about the same risk to life expectancy as smoking in the population of Belfast.

No analysis of the effect of different levels of cigarette smoking on life expectation in Britain or $\mathrm{N}$ Ireland has been published in this form. The effect of asbestos alone (or cigarette smoking alone) can be calculated only indirectly. The multiplicative model that fits the figures for lung cancer in American insulation workers may be applied to this small cohort. Assuming the mean effect of smoking in the general population is the same as the effect of asbestos in non-smoking insulation workers then the loss of life expectation for each alone is three to four years.* This would mean that the life expectation for non-smoking men in Belfast is about 75 years. Without the results of a direct analysis of the effect of cigarette smoking alone it is manifestly difficult to calculate the relative importance of other hazards, such as asbestos, on life expectation. Hammond at the World Conference on Smoking and Health of the American Cancer Society in New York in 1968 calculated that for American men cigarette smoking alone reduced the life expectation of young American men by four and a half to six years depending on the number of cigarettes smoked. Doll and Peto ${ }^{30}$ have calculated that British doctors lose five years of life by smoking 20 cigarettes a day.

\section{Prevention}

The dusty industries considered (coal, steel, and

*If $x=$ loss of life expectation due to smoking alone and asbestos exposure alone then the combined risk $=11+\mathrm{x}=$ $\mathrm{x}^{2}$. asbestos) could make a major contribution to respiratory disease in the community. There may be many smaller industries that cause respiratory illness either due to dust (as in the slate workers) or to a chemical as in the polyurethane plastics industry. Many of these have not been fully investigated, but these hazards of disease will probably be avoided by carefully controlling dust or fumes or by substituting safer materials. This will undoubtedly lead to the disappearance of certain traditional products, such as the roofing slate, because substitutes are cheaper and safer. As a result of removing many small contributions to society's burden of respiratory disease there may be a noticeable reduction in the total.

But in considering industries like coal and steel and to a lesser extent asbestos the importance of these industries in our economy must be borne in mind. The decision to increase the preventive measures to protect the health of these large numbers of workers must be weighed against the possibility that the product will be made too expensive, thereby causing employment to fall both in the industry itself and in the dependent industries. In the case of coal it seems unlikely that we will be able to substitute other sources of energy in the foreseeable future and therefore the cost of more efficient worker protection must be weighed against their gain in health. The question that must be answered is, "Is the cost-benefit relation such that this method of improving the community's respiratory health should be chosen in preference to the spending of an equivalent amount in reducing general atmospheric pollution or cigarette smoking?" In the iron and steel industry it seems that the environment has already been improved to the point at which no significant amount of chronic respiratory disease is produced. But research is needed to identify and eliminate the cause of the lung cancer in this industry.

Asbestos, although widely used, is not so essential as coal or steel. Some countries are attempting to do without it altogether. But this policy is open to two serious questions that have not yet been answered by scientific study. Firstly, are the substitutes as effective? One does not know, for instance, whether cement products reinforced with asbestos substitutes will be as efficient and will not fail structurally after time, stress, and weathering. Nor is it yet known whether brake linings will be as efficient or fire protection as effective. Secondly, the substitutes are not free from respiratory hazard, although work in hand indicates that up to the present time the man-made mineral fibre and ceramic fibre industry has not created as high a health risk as the asbestos industry.

Those making policy decisions on how to improve the health of the community have to consider these 
various factors. It is the responsibility of the medical profession to give accurate information on the relative importance of the various factors affecting health.

\section{Summary and conclusions}

Since the turn of the century the burden of respiratory disease on our community has changed. Some of the benefits have been due to improved social conditions and some to more effective medical care. There remains a serious level of disease and premature death due to chronic bronchitis and asthma that is unlikely to respond further to social change or to treatments available at present. The incidence of lung cancer has increased alarmingly. These three diseases, bronchitis, asthma, and lung cancer are at least in part due to materials inhaled into the lungs and to this extent are preventable.

Much has been done as a result of the Clean Air Act to improve the general level of atmospheric pollution, and this may be the reason for the recent improvement in morbidity and mortality for bronchitis. But the other two important sources of pollution of inhaled air (the work place and tobacco smoking) could be reduced further. In this age of financial stringency cost effectiveness is often the ultimate determinant as to which factor we should tackle first.

I have reviewed the evidence of the relative importance of smoking and dust in coal miners, slate quarry workers, iron and steel workers, and those working with asbestos. The evidence is scanty and in many instances unreliable. But it indicates that although dust may cause the symptoms of bronchitis in young men, these symptoms may persist but are unlikely to cause serious airways obstruction or premature aging of the lung (emphysema). In most cases smoking is the main cause of bronchitic symptoms in all age groups and may lead to airways obstruction and emphysema. Age by itself, representing the general environment, is less important than smoking but is usually more important than dust in causing disability. Heavy exposure to dusts may lead eventually to scarring of the lung and progressive disability. In the industries where a scientifically based effort has been made to control the dust exposure these serious consequences are being prevented. This appears to be true for the coal miners in Britain and may also be true for the lung fibrosis in asbestos workers. But whereas coal miners may now expect to live as long as other workers we are not in a position to be certain about steel workers or asbestos workers. Steel workers have an excess risk of lung cancer, the cause of which is not known or fully investigated. It is not as great as that due to cigarette smoking.

Lung cancer and mesothelioma of the pleura and peritoneum can result from exposure to asbestos. There is a long interval between critical exposure and the development of this tumour so that prevention takes a long time to show results. Measurements of past exposure in this industry have not been very meaningful so that the comparisons between the risks due to asbestos and the risks due to smoking are difficult. The situation is complicated by a synergism between tobacco smoke and asbestos in causing both lung cancer and disabling lung fibrosis (smoking does not contribute to mesothelioma). But it appears that in some of the groups who suffered from heaviest exposure before the current regulations the overall risk from asbestos was approximately equal to the overall risk from smoking.

Only in the archaic conditions of the slate industry did dust exposure exceed cigarette smoking in importance as a cause of disabling disease. In all the other situations reviewed cigarette smoking was the dominant cause of symptoms, of disability and of premature death from respiratory disease. Bearing in mind that smoking also causes serious cardiovascular disease there is no question that even in these dusty industries stopping smoking would have a far greater effect on the burden of disease than the complete suppression of all the dusts and fumes.

\section{References}

${ }^{1}$ Royal College of Physicians. Smoking and health. London: Pitman Medical, 1962

${ }^{2}$ Royal College of Physicians. Smoking and health now. London: Pitman Medical, 1971.

${ }^{3}$ Royal College of Physicians. Smoking or health. Tunbridge Wells: Pitman Medical, 1977.

${ }^{4}$ Gilson JC, Hugh-Jones P. Lung function in coalworkers' pneumoconiosis. London: HMSO, 1955. (Medical Research Council Special Report Series No 290.)

${ }^{5}$ Liddell FDK. Morbidity of British coal miners in 1961-2. Br J Ind Med 1973;30:1-14.

${ }^{6}$ Deutsche Forschungsgemeinschaft. Research report: chronic bronchitis and occupational dust exposure. Boppard: Boldt, 1978.

${ }^{7}$ Rogan JM, Attfield MD, Jacobsen M, Rae S, Walker DD, Walton WH. Role of dust in the working environment in development of chronic bronchitis in British coal miners. Br J Ind Med 1973;30:217-26.

8 Jacobsen M. Dust exposure, lung diseases, and coalminers' mortality. Edinburgh: University of Edinburgh, 1976. (PhD thesis.)

${ }^{9}$ Liddell FDK. Mortality of British coal miners in 1961. Br J Ind Med 1973;30:15-24.

${ }^{10}$ Cochrane AL, Haley TJL, Moore F, Hole D. The mortality of men in the Rhondda Fach, 1950-70. Br J Ind Med 1979;36:15-22.

${ }^{11}$ Rooke GB, Ward FG, Dempsy AN, Dowler JB, Whitaker CJ. Carcinoma of the lung in Lancashire coalminers. Thorax 1979;34:229-33. 
12 Registrar General. Decennial supplement England and Wales 1951. Occupational mortality. London: HMSO, 1958.

${ }^{13}$ Lloyd Davies TA. Respiratory disease in foundrymen. Report of a survey. London: HMSO, 1971.

14 Lowe CR, Campbell H, Khosla T. Bronchitis in two integrated steel works. III Respiratory symptoms and ventilatory capacity related to atmospheric pollution. $\mathrm{Br} J$ Ind Med 1970;27:121-9.

${ }^{15}$ Registrar General. Decennial supplement for England and Wales, 1970-2. Occupational mortality. London: HMSO, 1978. (Series DS No 1.)

${ }^{16}$ Grundy PF. Mortality amongst 5000 steelworkers in relation to smoking obesity lung function and respiratory symptoms. Cardiff: University of Cardiff, 1979. (MD thesis.)

17 Glover JR, Bevan C, Cotes JE, et al. Effects of exposure to slate dust in N Wales. Br J Ind Med 1980;37:152-62.

${ }^{18}$ Merewether ERA, Price CW. Report on the effects of asbestos dust on the lungs and dust suppression in the asbestos industry. London: HMSO, 1930.

19 Buchanan WD. Asbestosis and primary intrathoracic neoplasms. Ann NY Acad Sci 1965;132:507-18.

${ }^{20}$ Wagner JC, Sleggs CA, Marchand P. Diffuse pleural mesothelioma and asbestos exposure in the Northwestern Cape Province. Br J Ind Med 1960;17:260-71.

${ }^{21}$ McDonald JC. Epidemiology of asbestos related diseases. Biological effects of mineral fibres. Lyon: International Agency for Research in Cancer. (In press.)
${ }^{22}$ McDonald AD. Mineral content of lung in mesothelial tumours. Preliminary report. Biological effects of mineral fibres. Lyon: International Agency for Research in Cancer. (In press.)

${ }^{23}$ Newhouse ML, Berry G. Predictions of mortality from mesothelial tumours in asbestos factory workers. $\mathrm{Br} J$ Ind Med 1976;33:147-51.

${ }^{24}$ Weiss W. Cigarette smoking, asbestos and pulmonary fibrosis. Am Rev Respir Dis 1971;104:223-7.

${ }^{25}$ Rossiter CE, Berry G. The interaction of asbestos exposure and smoking on respiratory health. Bull Eur Physiopathol Respir 1978;14:197-204.

${ }^{26}$ Selikoff IJ, Hammond EC, Seidman H. Cancer risk of insulation workers in the United States. In: Bogovski P, Gilson JC, Timbrell V, Wagner JC, eds. Biological effects of asbestos. Lyon: International Agency for Research in Cancer, 1973:209-16.

27 Elmes PC, Simpson MJC. Insulation workers in Belfast. A further study of mortality due to asbestos exposure (194075). Br J Ind Med 1977;34:174-80.

${ }^{28}$ Saracci R. Asbestos and lung cancer: an analysis of the epidemiological evidence on the asbestos-smoking interaction. Int J Cancer 1977;20:323-31.

${ }^{29}$ Hammond EC, Selikoff IJ, Seidman H. Asbestos exposure, cigarette smoking and death rates. Ann NY Acad Sci. (In press.)

${ }^{30}$ Doll R, Peto R. Mortality in relation to smoking: 20 years' observations on male British doctors. $\mathrm{Br}$ Med J 1976;ii : 1525-36.

\section{Vancouver style}

All manuscripts submitted to the $B r J$ Ind Med should conform to the uniform requirements for manuscripts submitted to biomedical journals (known as the Vancouver style).

The $B r J$ Ind Med, together with many other international biomedical journals, has agreed to accept articles prepared in accordance with the Vancouver style. The style (described in full in Br Med J, 24 February 1979, p 532) is intended to standardise requirements for authors.

References should be numbered consecutively in the order in which they are first mentioned in the text by Arabic numerals above the line on each occasion the reference is cited (Manson ${ }^{1}$ confirmed other reports ${ }^{2-5} \ldots$. . In future references to papers submitted to the $\mathrm{Br} J$ Ind Med should include: the names of all authors if there are six or less or, if there are more, the first three followed by et al; the title of journal articles or book chapters; the titles of journals abbreviated according to the style of Index Medicus; and the first and final page numbers of the article or chapter.

Examples of common forms of references are:

${ }^{1}$ International Steering Committee of Medical Editors. Uniform requirements for manuscripts submitted to biomedical journals. Br Med J 1979;1:532-5.

2 Soter NA, Wasserman SI, Austen KF. Cold urticaria: release into the circulation of histamine and eosinophil chemotactic factor of anaphylaxis during cold challenge. N Engl J Med 1976;294:687-90.

${ }^{3}$ Weinstein L, Swartz MN. Pathogenic properties of invading micro-organisms. In: Sodeman WA Jr, Sodeman WA, eds. Pathologic physiology: mechanisms of disease. Philadelphia: W B Saunders, 1974:457-72. 